\title{
Percutaneous Permeation Enhancement by Terpenes: Mechanistic View
}

\author{
Bharti Sapra, ${ }^{1}$ Subheet Jain, ${ }^{1}$ and A. K. Tiwary ${ }^{1,2}$
}

Received 6 November 2007; accepted 22 January 2008; published online 8 February 2008

\begin{abstract}
A popular approach for improving transdermal drug delivery involves the use of penetration enhancers (sorption promoters or accelerants) which penetrate into skin to reversibly reduce the barrier resistance. The potential mechanisms of action of penetration enhancers include disruption of intercellular lipid and/or keratin domains and tight junctions. This results in enhanced drug partitioning into tissue, altered thermodynamic activity/solubility of drug etc. Synthetic chemicals (solvents, azones, pyrrolidones, surfactants etc.) generally used for this purpose are rapidly losing their value in transdermal patches due to reports of their absorption into the systemic circulation and subsequent possible toxic effect upon long term application. Terpenes are included in the list of Generally Recognized As Safe (GRAS) substances and have low irritancy potential. Their mechanism of percutaneous permeation enhancement involves increasing the solubility of drugs in skin lipids, disruption of lipid/protein organization and/or extraction of skin micro constituents that are responsible for maintenance of barrier status. Hence, they appear to offer great promise for use in transdermal formulations. This article is aimed at reviewing the mechanisms responsible for percutaneous permeation enhancement activity of terpenes, which shall foster their rational use in transdermal formulations.
\end{abstract}

KEY WORDS: DSC; FTIR; percutaneous permeation enhancement; terpene; transdermal.

\section{INTRODUCTION}

The skin acts as a barrier for diffusion of substances into the body. The main barrier for most substances is located in upper layer of skin, the stratum corneum (SC). The SC consists of keratin enriched dead cells, surrounded by crystalline intercellular lipid domains. These domains are continuous structures in the $\mathrm{SC}$ and are required for competent skin barrier function (1). To achieve and to maintain effective therapeutic plasma drug concentrations, the barrier properties of skin sometimes have to be overcome to enable successful delivery. Both physical approaches (stratum corneum stripping, stratum corneum hydration, electrically assisted transdermal drug delivery) and chemical approaches (synthesis of lipophilic analogue, delipidization of SC, coadministration of penetration enhancers) have been investigated for accomplishing this goal. Extensive research during the past two decades has revealed considerable information on several classes of penetration enhancers, including surfactants (e.g. tween; 2), fatty acids/esters (e.g. oleic acid; 3), solvents (e.g. dimethylsulfoxide, ethanol; 4) and terpenes (e.g. limonene; 5). Despite their fairly satisfactory performance in enhancing the permeation of drug molecule across the skin, chemical enhancers are viewed with suspicion

\footnotetext{
$\overline{{ }^{1} \text { Department of Pharmaceutical Sciences and Drug Research, }}$ Punjabi University, Patiala 147002, India.

${ }^{2}$ To whom correspondence should be addressed. (e-mail: aktiwary2@ rediffmail.com)
}

in transdermal formulations due to their irritancy potential when employed at concentrations necessary for achieving useful levels of penetration enhancement (6).

Efforts have been directed at identifying safe and effective enhancers from both natural products and synthetic chemicals. In particular, terpenes from natural sources and laboratory designed terpenoids have attracted great interest (7-9). Terpenes are generally considered to be less toxic with low irritancy potential compared to surfactants and other synthetic skin penetration enhancers. Further, quite a few terpenes are included in the list of Generally Recognized As Safe (GRAS) agents issued by US FDA $(9,10)$.

Terpenes can increase skin permeation by one or more of the mechanisms (Table I): interacting with SC lipids and/or keratin, and increasing the solubility of drug into SC lipids (9). However, the interaction of terpenes with SC in presence of various solvents may not be similar due to differences in the physico-chemical properties of these solvents and their interactions with SC. These interactions can be determined by instrumental methods, such as, differential scanning calorimetry (DSC) and Fourier transform infrared spectroscopy (FTIR). Table II summarizes the effect of several terpenes on thermotropic behaviour of skin. DSC thermograms of skin treated with permeation enhancers can be evaluated by comparing the endotherms and exotherms for mean transition temperature $\left(T_{\mathrm{m}}\right)$, cooperativity and their enthalpies $(\Delta H)$. Shifting of $T_{\mathrm{m}}$ of both lipid transitions $\mathrm{T} 2$ and $\mathrm{T} 3$ to lower temperature is generally ascribed to the disruption of lipid bilayer while the reduction in $\Delta H$ is associated with fluidization of lipid bilayers of SC $(28,29)$. Table III summa- 


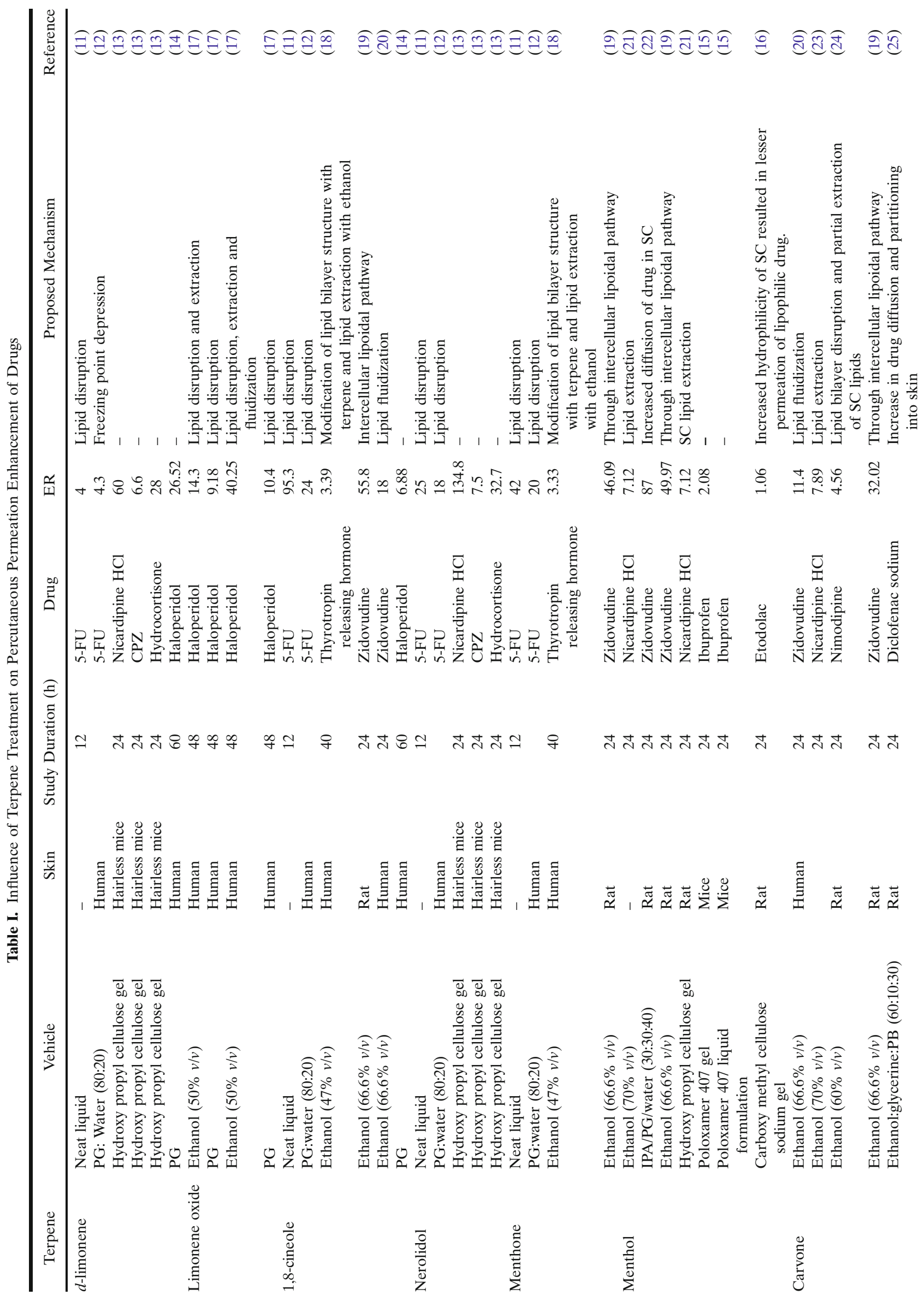




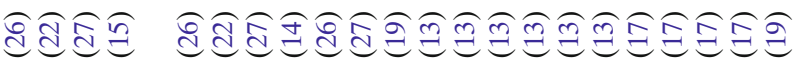


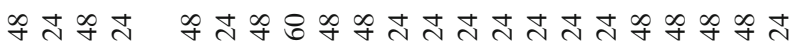

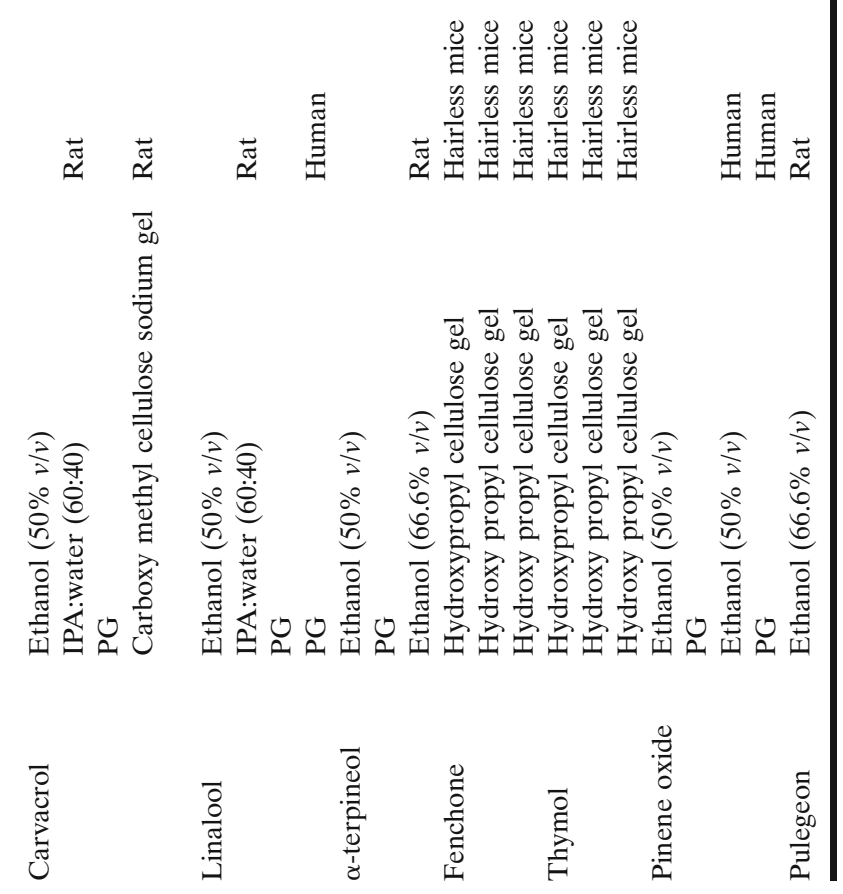

rizes the effects of several terpenes on the FTIR spectrum of skin. FTIR analysis provides information about the molecular and conformational changes in SC lipids and proteins. The asymmetric and symmetric $\mathrm{C}-\mathrm{H}$ vibrations obtained at 2,920 and $2,850 \mathrm{~cm}^{-1}$, respectively, have been ascribed to hydrocarbon lipid chains of SC. The height and area of these two peaks have been found to be proportional to the amount of lipids present in $\mathrm{SC}$ (32). The $\mathrm{C}=\mathrm{O}$ stretching vibration of lipid polar head groups produce a band near $1,740 \mathrm{~cm}^{-1}$. In addition, strong amide and water absorbance bands are found in region of 1,500-1,700 and 3,000$3,600 \mathrm{~cm}^{-1}$, respectively. The bands at 1,650 and $1,550 \mathrm{~cm}^{-1}$ have been suggested to arise from amide I and amide II stretching vibrations, respectively, of the SC proteins. The frequencies of these two bands, especially amide I band, are sensitive and shift to higher or lower frequencies according to the change in protein conformation (33). Therefore, both methods provide independent but complementary data about the interaction of terpenes with SC in the presence of different solvents.

These techniques can further be complemented with microscopic studies in order to assess the effect of terpenes on various domains of skin. Further, application of quantitative correlation between permeation effects and physicochemical descriptors of terpenes by QSAR models can provide insights into the possible mechanisms responsible for skin permeation enhancement activity.

In view of the renewed interest in herbal components, this article is aimed at reviewing the use of terpenes as drug penetration enhancers in transdermal drug delivery and to discuss the possible mechanisms for this activity.

\section{TERPENES AND TERPENOIDS}

Terpenes and terpenoids are usually the constituents of volatile oil. Several natural sources and their major terpene content are summarized in Table IV. The basic chemical structure consists of a number of repeated isoprene $\left(\mathrm{C}_{5} \mathrm{H}_{8}\right)$ units, which is used to classify terpenes. Thus, monoterpenes have two isoprene units $\left(\mathrm{C}_{10}\right)$, sesquiterpenes have three $\left(\mathrm{C}_{15}\right)$, and diterpenes have four $\left(\mathrm{C}_{20}\right)$, etc. Terpenes may also be classified as acyclic/linear, monocyclic and bicyclic.

Numerous terpenes have been used as antispasmodics, carminatives, flavoring agents, perfumes etc. For example, menthol is traditionally used in inhalation pharmaceuticals and has a mild antipruritic effect when incorporated into emollient preparations. However, the potential of terpenes as percutaneous absorption enhancer was suggested (5). Several cyclic terpenes like cineole, $d$-limonene, and $\alpha$-pinene have been intensively investigated as penetration enhancers.

\section{$d$-Limonene}

Okabe et al. reported the effect of ethanolic solution of $d$-limonene on percutaneous absorption of indomethacin and ketoprofen. Limonene was found to be essential for increasing the penetration of poorly permeable drugs. However, enhanced permeability of drugs cannot be easily maintained due to difficulty in sustaining high activity of enhancers during the applied period $(36,37)$. In order to maintain the 
Table II. Influence of Terpene Treatment on Thermotropic Attributes of Drugs

\begin{tabular}{|c|c|c|c|c|c|c|c|c|c|}
\hline \multirow[b]{3}{*}{ Terpene } & \multirow[b]{3}{*}{ Vehicle } & \multirow[b]{3}{*}{ Drug } & \multirow[b]{3}{*}{$T_{\mathrm{m}}\left({ }^{\circ} \mathrm{C}\right)$} & \multicolumn{4}{|c|}{ Thermotropic Attributes } & \multirow[b]{3}{*}{ Proposed Mechanism } & \multirow[b]{3}{*}{ Ref. } \\
\hline & & & & \multicolumn{2}{|l|}{$\mathrm{T} 2$} & $\mathrm{~T} 3$ & $\mathrm{~T} 4$ & & \\
\hline & & & & $\% \Delta H(\mathrm{~J} / \mathrm{g})$ & $T_{\mathrm{m}}\left({ }^{\circ} \mathrm{C}\right)$ & $\% \Delta H(\mathrm{~J} / \mathrm{g})$ & $T_{\mathrm{m}}\left({ }^{\circ} \mathrm{C}\right)$ & & \\
\hline \multirow[t]{4}{*}{$d$-limonene } & Neat liquid & $5-\mathrm{FU}$ & -23 & NS & -16 & NS & Increased & Lipid disruption & (11) \\
\hline & PG/W (20:80) & $5-\mathrm{FU}$ & -22 & & -13 & & & $\begin{array}{l}\text { Freezing point } \\
\text { depression }\end{array}$ & (12) \\
\hline & PG/W (50:50) & $5-\mathrm{FU}$ & -23 & & -15 & & & $\begin{array}{l}\text { Freezing point } \\
\text { depression }\end{array}$ & (12) \\
\hline & PG/W (80:20) & $5-\mathrm{FU}$ & -24 & & -15 & & & $\begin{array}{l}\text { Freezing point } \\
\text { depression }\end{array}$ & (12) \\
\hline \multirow[t]{4}{*}{ 1,8-cineole } & Neat liquid & $5-\mathrm{FU}$ & -23 & 50 & -16 & 50 & Increased & Lipid disruption & (11) \\
\hline & PG/W (20:80) & $5-\mathrm{FU}$ & -24 & 18 & -18 & NS & NS & Lipid disruption & (12) \\
\hline & PG/W (50:50) & $5-\mathrm{FU}$ & -24 & 37 & -17 & NS & NS & Lipid disruption & (12) \\
\hline & PG/W (80:20) & $5-\mathrm{FU}$ & -28 & 60 & -17 & 22 & NS & Lipid disruption & (12) \\
\hline \multirow[t]{4}{*}{ Nerolidol } & Neat liquid & $5-\mathrm{FU}$ & -4.2 & Increased & -4 & Increased & Absent & Lipid disruption & (11) \\
\hline & PG/W (20:80) & $5-\mathrm{FU}$ & -3 & 6 & -4 & NS & NS & Lipid disruption & (11) \\
\hline & PG/W (50:50) & $5-\mathrm{FU}$ & -4 & 15 & -4 & NS & NS & Lipid disruption & (12) \\
\hline & PG/W (80:20) & $5-\mathrm{FU}$ & -6 & 30 & -8 & NS & NS & Lipid disruption & (12) \\
\hline \multirow[t]{4}{*}{ Menthone } & Neat liquid & $5-\mathrm{FU}$ & -19.4 & Increased & -10 & Increased & Absent & Lipid disruption & (11) \\
\hline & PG/W (20:80) & $5-\mathrm{FU}$ & -15 & 8 & -14 & NS & NS & Lipid disruption & (11) \\
\hline & PG/W (50:50) & $5-\mathrm{FU}$ & -15 & 17 & -15 & NS & NS & Lipid disruption & (12) \\
\hline & PG/W (80:20) & $5-\mathrm{FU}$ & -16 & 42 & -15 & NS & NS & Lipid disruption & (12) \\
\hline Menthol & EtOHl $(70 \% v / v)$ & Nicardipine $\mathrm{HCl}$ & NS & Decreased & Absent & Absent & Absent & Lipid extraction & (21) \\
\hline Carvone & EtOH $(70 \% v / v)$ & Nicardipine $\mathrm{HCl}$ & NS & Decreased & Absent & Absent & Absent & Lipid extraction & (21) \\
\hline \multirow[t]{2}{*}{ Carvacrol } & EtOH $(50 \% v / v)$ & Haloperidol & -16 & Increased & -12 & Decreased & +20 & $\begin{array}{l}\text { Lipid disruption } \\
\text { and extraction }\end{array}$ & (26) \\
\hline & PG & & -5 & NS & -7 & Decreased & Absent & $\begin{array}{l}\text { Lipid disruption } \\
\text { and extraction }\end{array}$ & $(27)$ \\
\hline \multirow[t]{2}{*}{ Linalool } & $\mathrm{EtOH}(50 \% v / v)$ & Haloperidol & -32 & Decreased & -15 & Decreased & -5 & $\begin{array}{l}\text { Lipid disruption } \\
\text { and extraction }\end{array}$ & (26) \\
\hline & PG & & -5 & NS & -3.5 & Decreased & Absent & $\begin{array}{l}\text { Lipid disruption } \\
\text { and extraction }\end{array}$ & $(27)$ \\
\hline \multirow[t]{2}{*}{$\alpha$-terpeniol } & $\mathrm{EtOH}(50 \% v / v)$ & Haloperidol & -32 & Decreased & -23 & NS & -12 & $\begin{array}{l}\text { Lipid disruption } \\
\text { and extraction }\end{array}$ & (26) \\
\hline & PG & & -5 & NS & -3.5 & Decreased & +10 & $\begin{array}{l}\text { Lipid disruption } \\
\text { and extraction }\end{array}$ & $(27)$ \\
\hline \multirow[t]{2}{*}{ Limonene oxide } & $\mathrm{EtOH}(50 \% v / v)$ & Haloperidol & & Coalescence & & Coalescence & Absent & $\begin{array}{l}\text { Lipid disruption } \\
\text { and extraction }\end{array}$ & (17) \\
\hline & PG & & -2 & NS & -3 & & Absent & Lipid disruption & (17) \\
\hline \multirow[t]{2}{*}{ Pinene oxide } & $\mathrm{EtOH}(50 \% \mathrm{v} / \mathrm{v})$ & Haloperidol & -26 & Decreased & -24 & NS & Absent & $\begin{array}{l}\text { Lipid disruption } \\
\text { and extraction }\end{array}$ & (17) \\
\hline & PG & & -5.5 & Decreased & -6 & Decreased & Absent & Lipid fluidization & $(17)$ \\
\hline
\end{tabular}

NS Not significant, 5-FU 5-fluorouracil, $P G$ propylene glycol, Et $O H$ Ethanol, $w$ water

activity of the enhancer, Okabe et al. (5) employed a rate limiting membrane to control the permeation of ethanol used along with $d$-limonene. The cooperative effect of ethanol and $d$-limonene was reported to be an effective binary enhancer system $(5,37,38)$. The enhancement of ethanol released on addition of $d$-limonene was found to be due to a change in structure of the adhesive layer of the transdermal patch because of its high affinity for $d$-limonene. The formulated system yielded high steady state permeation of drugs for a long period. The enhancement action was mainly attributed to the improved diffusivity of indomethacin in skin because the lag time for permeation was greatly shortened (5).

Ohara et al. evaluated the combined effect of $d$-limonene and temperature on the skin permeation of ketoprofen across rat skin. The apparent penetration rate $\left(R_{\mathrm{p}}\right)$ increased sigmoidally with increase in the temperature, and at lower temperature $R_{\mathrm{p}}$ was almost constant. A linear relationship was observed when the skin was pretreated with $30 \% \mathrm{v} / \mathrm{v}$ ethanol without $d$-limonene. However, Arrhenius plots of permeability coefficient value obtained after skin pretreatment with $1.5 \% \mathrm{w} / v d$-limonene in $30 \% v / v$ ethanol exhibited a convex curvature, suggesting that skin structure was altered with increase in temperature (39).

Krishnaiah et al. evaluated a limonene-based transdermal therapeutic system for its ability to provide the desired steady state plasma concentration of nicorandil in human volunteers. The flux of nicorandil from the limonene-based hydroxy propyl methyl cellulose drug reservoir across EVA 2825 (Ethylene vinyl acetate coated with $28 \%$ copolymers) membrane decreased to $216 \pm 10 \mu \mathrm{g} / \mathrm{cm}^{2} / \mathrm{h}$ as compared to control $\left(371 \pm 4 \mu \mathrm{g} / \mathrm{cm}^{2} / \mathrm{h}\right)$ indicating that EVA 2825 effectively functioned as a rate controlling membrane. The 
limonene-based drug reservoir was sandwiched between an adhesive coated EVA 2825-release liner composite and a backing membrane, and was heat-sealed to form a circular patch $\left(20 \mathrm{~cm}^{2}\right)$. This patch yielded a steady state plasma concentration of $21.3 \mathrm{ng} / \mathrm{ml}$ through $24 \mathrm{~h}$ in healthy human volunteers (40). Hydrocarbon limonene was found to be more effective as penetration enhancer as compared to oxygenated linalool and cineole because it produced 26.5fold greater permeation than control. Incorporation of limonene into an organogel-containing transdermal patch was observed to successfully deliver haloperidol at a sustained rate (14).

Limonene was reported to enhance the permeation of nicardipine $\mathrm{HCl}$ (hydrophilic) and hydrocortisone (polar steroid) significantly higher as compared to fenchone and thymol. These findings conflicted with the results observed by other researchers. It has been recognized that hydrophilic terpenes capable of hydrogen bonding (such as fenchone and thymol) actively promoted the permeation of hydrophilic drugs, whereas, hydrocarbon terpenes (e.g. limonene) provided higher permeation for lipophilic drugs $(41,42)$. It was revealed that the lipophilicity of the permeant, as well as the enhancer molecule played an important role in determining the penetration promoting activity $(13,41,43-50)$.

\section{Cineole}

The effects of propylene glycol (PG)/water co-solvent systems and terpene penetration enhancers [1,8-cineole, menthone, nerolidol and (+)-limonene] on the absorption rate of 5-FU (a hydrophilic permeant) were investigated using excised human skin. Co-application of each terpene in PG co-solvent system significantly enhanced the permeation of 5-FU. The penetration-enhancement activity of terpene depended on the propylene glycol content in the vehicle. Maximum permeation of 5-FU was obtained from formulations containing terpenes dispersed in $80 \%$ PG, which when normalized to the flux obtained using respective PG-water mixture yielded enhancement ratios ranging from 24 to 4 fold, respectively, for 1,8-cineole and (+)-limonene. The data obtained from DSC analysis was analyzed to calculate the entropy change in skin lipids after treatment with different terpenes. The treatment with 1,8-cineole, menthone and nerolidol was found to produce less change in the entropy (as compared to control) of skin lipids than the treatment with (+)-limonene. This indicated fluidization or reduction in lipid order at normal skin temperature. However, the observed higher entropy change of skin lipids after treatment with (+)-limonene than the control was suggested to be predominantly indicative of freezing point depression effect. Therefore, the mild effect of freezing point depression of skin lipids after treatment with (+)-limonene was able to enhance the permeation of 5-FU only by 4-fold as compared to 24 -fold enhancement produced by 1,8-cineole (12).

The addition of cineole $(3 \% \mathrm{w} / \mathrm{v})$ to ethanol $(47 \% \mathrm{v} / \mathrm{v})$ increased the penetration of thyrotropin releasing hormone (TRH) across human epidermis to $0.92 \pm 0.03 \mu \mathrm{g} / \mathrm{cm}^{2} / \mathrm{h}$ from $0.27 \pm 0.01 \mu \mathrm{g} / \mathrm{cm}^{2} / \mathrm{h}$. Although, carveol $(3 \% w / v)$ and menthone $(3 \% w / v)$ in combination with ethanol $(47 \% v / v)$ increased the permeation of TRH to $1.07 \pm 0.02 \mu \mathrm{g} / \mathrm{cm}^{2} / \mathrm{h}$ and $1.05 \pm 0.03 \mu \mathrm{g} / \mathrm{cm}^{2} / \mathrm{h}$, respectively, cineole showed most rapid attainment of steady state flux. It was interesting to note that neither ethanol alone nor the combination of any of the terpene and ethanol had any significant effect on the flux of TRH during a $2-4 \mathrm{~h}$ period. This suggested that the initial binding and saturation of the epidermal membrane by TRH was not affected by these materials (18).

Various oxygen-containing monoterpenes enhanced the transdermal flux of zidovudine in the following order: cineole $>$ menthol $>$ menthone $\sim$ pulgeone $\sim \alpha$-terpeniol $>$ carvone. SC or vehicle partition-coefficient of zidovudine was not altered significantly $(p>0.05)$ but the lag time required for zidovudine permeation was significantly reduced by all these terpenes. No significant difference in flux between vehicles, $1 \%$ or $2.5 \% w / v$ cineole was observed. As concentration of cineole was further increased to $5 \%$ and $10 \% \mathrm{w} / \mathrm{v}$ in vehicle, the flux was significantly enhanced by 56 -fold and 65 -fold, respectively. The observed difference in permeation enhancement activity was attributed to different thermodynamic activity of terpenes in the vehicle (19). In another investigation, 1,8-cineole was found to increase the flux of zidovudine 18-fold but lag time also increased from 4.9 to $8.5 \mathrm{~h}$ (20). Recent studies conducted by Heard revealed that enhancement of mefenamic acid using 1,8-cineole was due to "drag" or "pull" effect (51). However, another study suggested intercalation of cineole into lipids and proteins by forming hydrogen bonds thus, altering the organization of SC (52).

\section{Carvone}

The permeation of nicardipine $\mathrm{HCl}$ was observed to increase markedly by incorporating carvone in hydroxypropylcellulose gel and a maximum flux of $244 \pm 2 \mu \mathrm{g} / \mathrm{cm}^{2} / \mathrm{h}$ was observed with an enhancement ratio of 7.9 when $12 \% \mathrm{w} / \mathrm{w}$ carvone was used as enhancer. The enhancement was attributed to partial lipid extraction of the SC (23). The transdermal permeation of nimodipine across rat abdominal skin was found to increase from $1.67 \pm 0.03 \mathrm{mg} / \mathrm{cm}^{2} / 24 \mathrm{~h}$ to $3.68 \pm 0.06 \mathrm{mg} / \mathrm{cm}^{2} / 24 \mathrm{~h}$ when carvone $(2 \%$ to $12 \% \mathrm{w} / \mathrm{w}$ ) was used with HPMC gel. However, no significant difference in the permeability coefficient of nimodipine was observed by incorporating $12 \% \mathrm{w} / \mathrm{w}$ carvone $(10.9 \pm 0.08)$ as compared to that obtained with $10 \% \mathrm{w} / \mathrm{w}$ of carvone $\left(10.73 \pm 0.5 \mathrm{~cm} / \mathrm{h} \times 10^{3} ; 24\right)$.

\section{Menthol}

Menthol, a monocyclic monoterpene free from significant toxic effects, has been approved as a penetration enhancer in the transdermal delivery of several drugs (5355). Kabayashi et al. evaluated the combined effects of 1menthol and ethanol as skin permeation enhancer, and derived two equations describing the permeability coefficient through full-thickness skin $\left(P_{\mathrm{FT}}\right)$ and the full-thickness skin/ vehicle concentration ratio $\left(C_{\mathrm{FT}} / C_{\mathrm{V}}\right)$ of drugs as a function of their octanol/vehicle partition coefficient $\left(K_{\mathrm{OV}}\right)$. A two-layer model was applied for skin. A nonlinear least-squares method was employed to determine six coefficients (three diffusion coefficients, the porosity of the SC, and two terms of the linear free energy relationship) using the two equations and experimentally obtained $P_{\mathrm{FT}}$ and $C_{\mathrm{FT}} / C_{\mathrm{V}}$ values. Addition of $l$-menthol to water or ethanol $(40 \%)$ improved the diffusion coefficient of morphine hydrochloride, atenolol, nifedipine 


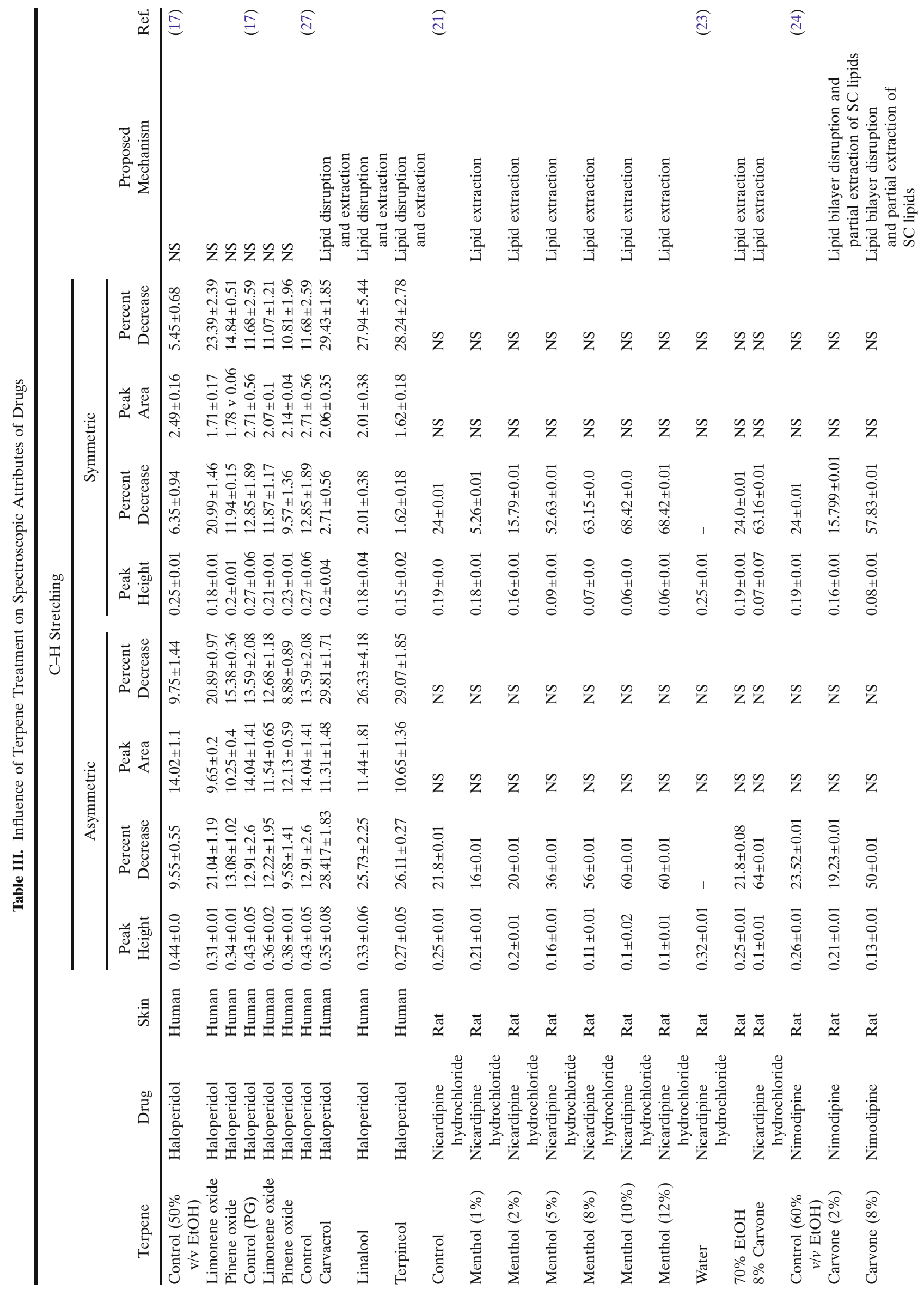


ब्व
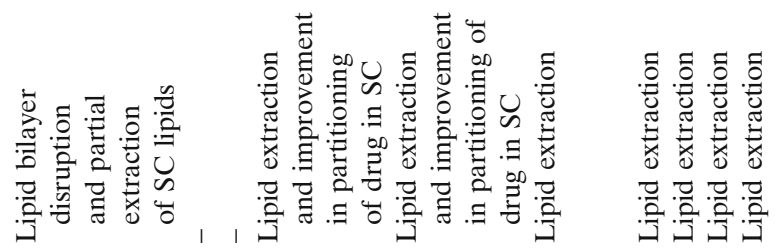

$n$
$z$
$z$
$z$
0
0
$0+1$
0
0
0
0
0
0
+1
5
0
0

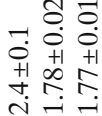

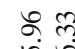

$\stackrel{+}{\mathfrak{d}}$

ำ

公公公公兄

径没设设

$\stackrel{1}{10}$

I लें 文

$n$
กิ
$\circ$
0
+
$\circ$

$\stackrel{0}{0}$
$\dot{0}$



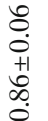

0
0
0
+1
0
0
0

$\infty$ in

in

ले ले ले स्था थ

乏

$\tilde{z}$

-1:

กิ

0 in

\begin{tabular}{l}
5 \\
0 \\
0 \\
+1 \\
0 \\
in \\
0 \\
0 \\
0 \\
0 \\
+1 \\
\hline
\end{tabular}

sin

।



$\stackrel{\vec{\pi}}{\simeq}$

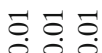

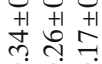

를 है:

:
$: \overline{0}$
:

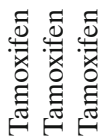

気

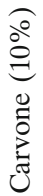

and vinpocetine in lipid and pore pathways of the SC, whereas addition of ethanol to water and $l$-menthol $(5 \%)$ improved the solubility of drugs in the vehicle and increased the contribution of the pore pathway towards whole skin permeation (56).

The mechanism of $l$-menthol as an enhancer was examined using diclofenac as a hydrophobic drug and diclofenac sodium as a hydrophilic drug through ethanoltreated and untreated silicone membranes. Results indicated that $l$-menthol enhanced the permeation of both salts of drug through both lipid as well as pore pathways (57).

Menthol has been shown to increase the skin absorption of testosterone by forming a eutectic mixture, thereby lowering its melting point drastically from $153.7^{\circ} \mathrm{C}$ to $39.9^{\circ}$ $\mathrm{C}$, as reflected by DSC studies. Hence, the skin permeation enhancement of testosterone by menthol was suggested to be due to increase in the solubility of testosterone accompanied with altered barrier properties of SC (53).

Hydrogel-based patches of propranolol hydrochloride were formulated with and without $(1 \%, 5 \%, 10 \% w / v)$ menthol as an enhancer. Permeation of propranolol hydrochloride across hairless mouse skin was significantly higher ( $p$ $<0.05)$ from patches containing menthol. This observation might be due to the preferential distribution of menthol into the intercellular spaces of SC, which resulted in reversible disruption of SC lipid domains (54).

In combination with $15 \% v / v$ ethanol, $l$-menthol $(1 \% w /$ $v$ ) increased the permeability coefficient of methyl paraben about 16-fold, while it decreased the permeability coefficient of butyl paraben to $20 \%$ of the control value through guinea pig dorsal skin. A spin label study with SC showed that these enhancers increased the lipid bilayer fluidity and led to enhanced permeation of hydrophilic substances (55).

Krishnaiah et al. observed marked enhancement in permeation of nicardipine hydrochloride from gel systems containing menthol $(1-12 \% \mathrm{w} / \mathrm{w})$ through excised rat epidermis. The cumulative amounts of nicardipine hydrochloride that permeated over $24 \mathrm{~h}$ increased from $1.74 \pm 0.13$ to $5.03 \pm$ $0.03 \mathrm{mg} / \mathrm{cm}^{2} / 24 \mathrm{~h}$ from the hydroxypropyl cellulose gels containing menthol. However, a lag period of $2-3 \mathrm{~h}$ in the permeation of the drug was observed. The flux remained constant when menthol was employed at $2 \% w / w$ concentration. However, when concentrations greater than $5 \% w / w$ were used, there was a rapid increase in flux (21). In addition, the study revealed that enhancement remained unaltered from the gel containing more than $8 \% w / w$ of menthol. There was a statistically insignificant $(p>0.05)$ decrease in enhancement of drug permeation with 10 or $12 \%$ w/w of menthol. Menthol is reported to increase both the moisture uptake capacity as well as release rate of propranolol hydrochloride from polymeric films (21). Further $l$-menthol $(5 \% w / v)$ was found to significantly $(p<0.05)$ enhance the pseudo steady state flux of zidovudine across human cadaver skin with an enhancement factor of 53. However, the lag time was observed to increase. Partitioning of $l$-menthol into skin was found to be poor thereby indicating that it might have lipid fluidizing activity on SC lipids (20). Chang et al. evaluated a series of terpenes as enhancers for meloxicam gel. Maximum flux was obtained when menthol was used as permeation enhancer and its enhancing activity was attributed to its hydrogen bonding ability (58). However, the study conducted 
Table IV. Major Components of Terpenes From Natural Sources

\begin{tabular}{|c|c|c|c|}
\hline Source & Botanical Name & Main Terpene Component & Ref. \\
\hline Angelica root & Angelica archngelica & $\beta$-Phellandrene, $\alpha$-phellandrene, $\alpha$-pinene & $(34)$ \\
\hline Anisi stellati fructus & Illicium verum & Monoterpenoid hydrocarbon (limonene, $\alpha$-pinene) & (34) \\
\hline Apti fructus & Apium graveolens & Limonene & (34) \\
\hline Basilici herba & Osimum basilicum & Linalool eugenol, scimene, cineole & $(34)$ \\
\hline Cajuput & Melaleuca leucadendron & 1,8-cineole, $\alpha$-terpineol, $d$-limonene & $(35)$ \\
\hline Cardamom & Elettaria cardamomum & 1,8-Cineole, $\alpha$-terpineol, $\alpha$-terpinyl acetate & (35) \\
\hline Carvi fructus & Carum carvi & $\begin{array}{l}(S)-(+) \text {-Carvone, }{ }^{\circledR}-(+) \text {-limonene, } \alpha \text {-pinene, } \\
\text { cpinene, dihydrocarvone, dihydrocaveol }\end{array}$ & (34) \\
\hline Caryophylli flos & $\begin{array}{l}\text { Eugenia caryophyllus, } \\
\text { Caryophyllus aromaticus }\end{array}$ & $\begin{array}{l}\text { Eugenol, eugenol acetate, } \alpha \text {-pinene, } \\
\beta \text {-caryophyllene and its oxide }\end{array}$ & $(34)$ \\
\hline Coriandri fructus & Coriandrum sativum & $\begin{array}{l}\text { D-(+)-linalool, monoterpene hydrocarbons } \\
\quad(\alpha \text {-pinene, } d \text {-limonene, } \gamma \text {-terpinene, } \rho \text {-cymene }\end{array}$ & $(34)$ \\
\hline Eucaluptus folium & Eucalyptus globulus & $\begin{array}{l}\text { 1,8-Cineole, eucalyptol, moderate amounts of monoterpenes } \\
(\rho \text {-cymene, } \alpha \text {-pinene }\end{array}$ & $(34)$ \\
\hline Foeniculi fructus & Foeniculum vulgare & $\begin{array}{l}\text { Trans-anethol, some terpenoid hydrocarbons ( } \alpha \text {-pinene, } \\
\alpha \text {-phellandrene }\end{array}$ & $(34)$ \\
\hline Juniperi fructus & Juniperus communis & $\begin{array}{l}\alpha \text {-Pinene, } \beta \text {-pinene, limonene, terpinen-4-ol, } \alpha \text {-terpineol, } \\
\text { borneol, geraniol }\end{array}$ & $(34)$ \\
\hline Melissa & Melissa officinalis & Geranial, neral & $(35)$ \\
\hline Melissae folium & Melissa officinalis & $\begin{array}{l}\text { Monoterpenes (citronellal, citral A, citral B),sesquiterpene } \\
(\beta \text {-caryophyllene, germacrene D) }\end{array}$ & $(34)$ \\
\hline Myrtle & Myrtus communis & 1,8-Cineole, $\alpha$-pinene, myrtenyl acetate & $(35)$ \\
\hline Niaouli & Melaleuca virdiflora & 1,8-Cineole, $\alpha$-pinene, $\alpha$-terpineol, $d$-limonene & $(35)$ \\
\hline Orange & Citrus aurantium & $d$-Limonene & (35) \\
\hline
\end{tabular}

by Anjos and coworkers revealed that $l$-menthol stabilized mainly in the central region of stratum corneum membranes, which interacted with the membrane lipids and resulted in disruption of hydrogen bonds in the polar membrane interface (59). The combination of menthol and iontophoresis was suggested to enhance the in vitro permeation of methotrexate due to alteration of lipidprotein domains of mice skin (60).

Few studies aimed at synthesizing $o$-alkyl and $o$ acylmenthol derivatives for increasing the permeation of drugs through skin. Among the synthesized compounds $o$ ethylmenthol (MET) showed greatest drug penetration activity and caused relatively little skin irritation (61). The flux of ketoprofen was markedly increased by using small amount of MET. It was concluded that MET increased retention of drugs in the skin surface (62). Obata et al. (63) evaluated MET for their structural activity relationships employing an artificial neural network. Confocal scanning

Table V. $\log p$ Values of Few Terpenes (85)

\begin{tabular}{lclc}
\hline Terpene & $\log p$ Value & Terpene & $\log p$ Value \\
\hline Carveol & 2.68 & $(S)$ - $(-)$-citronellal & 3.48 \\
(-) dihydro carveol & 2.92 & Carvacrol & 3.28 \\
(+)-dihydro carveol & 2.92 & Citral & 3.17 \\
$(+)$-dihydrocarvone & 2.47 & Menthone & 2.63 \\
$( \pm)$-linalool & 3.28 & Nerol & 3.28 \\
$(R)$-(-)-carvone & 2.27 & Thymol & 3.28 \\
$(R)$-(+)-pulgeone & 2.56 & $\beta$-cittronellal & 3.38 \\
Phytol retinol & 8.66 & $\beta$-carotene & 15.51 \\
Squalene & 13.09 & $( \pm)$-nerolidol & 5.31 \\
\hline
\end{tabular}

laser microscopy revealed that MET contributed to enhancement by lipid perturbation, thus enhancing drug diffusivity in skin lipids (64).

\section{Nerolidol}

The effects of fenchone, thymol, $d$-limonene and nerolidol on the percutaneous permeation of gel formulations of nicardipine hydrochloride, hydrocortisone, carbamazepine and tamoxifen were studied across hairless mouse skin. Nerolidol was found to be most effective in promoting permeation of all drugs (13). The results were in accordance with other studies conducted for 5-FU (65) and diclofenac sodium (66). According to Cornwell and Barry, the effective permeation promoting activity of nerolidol was due to its amphiphilic structure that was suitable for alignment within the lipid lamellae and also for disruption of the highly organized packing of SC (67). Nerolidol, at $2 \% w / v$ concentration was found to produce a 2-fold and 20-fold increase in the permeation of enoxaparin sodium (68) and 5-FU (65), respectively. An unsaturated sesquiterpene, $\alpha$-bisabolol was reported to enhance permeation of 5-FU and triamcinolone acetonide by 17 - and 73 -fold across excised human skin due to lipid fluidization of SC (69).

\section{QUANTITATIVE STRUCTURAL ACTIVITY RELATIONSHIP (QSAR)}

QSAR has been explored for relating the skin permeation of compounds to their physicochemical properties (70). In 1990, Flynn compiled skin permeability coefficients across human skin from different literature sources and identified $\log \mathrm{P}$ as the most important factor for determining the 
permeability coefficients (71). The subsequent QSAR studies raised interest in using QSAR for modeling skin permeation (70,72-82). These QSAR models provide an insight into the mechanism of skin penetration and guidance for predicting permeability of new compounds.

Ghafourian et al. constructed QSAR models for 34 terpenes, 16 pyrrolidinone derivatives and seven $\mathrm{N}$-acetylprolinate esters with respect to several drugs (83). These QSAR models were based on data of different sources and skin types, including human, rats and hairless mouse skins. However, the data needs more careful analysis when combined into a single dataset as it is difficult to explain the large variations, primarily due to inter-laboratory differences such as skin sample types and sources, solvent systems for enhancers and experimental protocols.

The $\log p$ value of terpene (Table $\mathrm{V}$ ) appears as a predictor in many QSAR models $(70,84)$. Kang et al. determined permeability coefficient of different terpenes experimentally using human skin and employed non-linear regression model. Their results suggested that (1) liquid terpenes tend to produce better enhancing effects than solid terpenes; (2) triterpenes and tetraterpenes generally had poor penetration effect than other terpenes; (3) terpenes with larger $\log p$ values were more effective enhancers than those with smaller $\log \mathrm{P}$ as it was easier for lipophilic terpenes to get mixed with SC intercellular lipids (for extraction or for lipid phase transition; 19,83,85,86); (4) the liquid terpenes could form more number of hydrogen bonds with intercellular lipids of SC $(20,25,85)$; (5) terpenes with aldehyde and ester functional groups were found to be better enhancers (85). In addition, the size of a terpene also determined the penetration ability. Smaller terpenes tended to be more active than the larger terpenes (86). Furthermore, smaller alcoholic terpenes with a higher degree of unsaturation appeared to be good candidates for enhancing the permeation of hydrophilic drugs (83). Cal and his coworkers investigated the absorption and elimination of different terpenes from human skin layers and observed terpinen-4-ol to accumulate in the skin to a greater extent when compared to pinenes ( $\alpha$ and $\beta$ pinene) and eucalyptol. This property was ascribed to the presence of polar groups, which increased its affinity towards polar region of SC and hydrophilic dermis. Almost negligible penetration was observed for pinenes in spite of the same $\log p$ values (87). Fang et al. concluded that oxygen containing terpenes were more effective than hydrocarbon terpenes. In addition, oxygen containing terpenes with a bicyclic structure displayed a lesser permeation enhancing effect (88).

\section{IN VITROIIN VIVO CORRELATIONS}

Though the ultimate goal of enhancing percutaneous absorption relates to humans, in vivo studies are not always possible, for various reasons. Although comparative studies of in vitro and in vivo absorption through animal models or human skin are limited, the existing data strongly support the relevance of in vitro data.

The investigations of Karali et al. revealed azidothymidine to be delivered systemically from transdermal gel formulation containing carvone at rate of $0.9 \mathrm{mg} / \mathrm{cm}^{2} / 24 \mathrm{~h}$ in rats. In order to achieve the minimum effective concentration of azidothymidine in humans $(0.27 \mu \mathrm{g} / \mathrm{ml})$, a delivery rate of $1 \mathrm{mg} / \mathrm{cm}^{2} / \mathrm{h}$ from transdermal patch of $25 \mathrm{~cm}^{2}$ in size was needed. Therefore, these studies demonstrated the inability of carvacrol to achieve the required delivery rate of azidothymidine in humans (22). Another investigation, however, demonstrated in vitro flux ranging from 1.03 to $1.79 \mathrm{mg} / \mathrm{cm}^{2} / \mathrm{h}$ across rat skin by using hydro alcoholic solutions of various terpenes as permeation enhancers. The magnitude of permeation rates documented in this study show a great promise of terpenes in achieving the required systemic delivery rate of azidothymidine in humans (19).

In vitro permeation studies of nicorandil across rat abdominal skin from transdermal formulations containing carvone or limonene revealed, respectively, 1.6-fold and 1.7fold greater permeation than that required for achieving their systemically effective concentration in rats. However, the observed enhancement (1.6-fold) of permeation of nicorandil across rat skin did not seem capable of providing effective plasma concentration in humans due to the higher resistance of human SC, which is three times less permeable than rat skin $(40,89)$. Nevertheless, using carvone as enhancer and adhesive-coated EVA 2825 membrane, the average steady state of $20.5 \mathrm{ng} / \mathrm{ml}$ in humans was maintained through $24 \mathrm{~h}$ (89). The lag time was observed to reduce to $2.8 \mathrm{~h}$ and a steady state plasma concentration of nicorandil was maintained at $21.3 \mathrm{ng} / \mathrm{ml}$ through $24 \mathrm{~h}$ when limonene was employed as enhancer and adhesive-coated EVA 2825 as rate controlling membrane (40).

The suitability of adhesive-coated EVA 2825 membrane using limonene (90) or menthol (91) as enhancers for nicardipine hydrochloride was tested by employing excised rat skin. Limonene or menthol enhanced the in vitro permeation of nicardipine hydrochloride, respectively, by 2.08 -fold and 1.8-fold. The systemic delivery of nicardipine hydrochloride in humans was maintained by limonene or menthol, respectively, at 32.1 or $21.2 \mathrm{ng} / \mathrm{ml}$. Limonene maintained the plasma steady state concentration over $20 \mathrm{~h}$, while menthol maintained it over $26 \mathrm{~h}$. Although, these patches were not evaluated for their effectiveness from pharmacodynamic view point, their ability to maintain constant drug level in plasma of human volunteers suggested sustained systemic drug delivery $(90,91)$.

\section{TERPENES AND THEIR DISPOSITION}

Despite the ubiquitous occurrence and importance of terpenes in food, little is known about their metabolic fate. After ingestion, terpenes are well absorbed and metabolized via hydroxylation or epoxidation by microsomal monooxidases. The primary metabolites are further transformed into more polar compounds and are excreted via urine. Most of the data available pertains to rat $(92-95)$ or rabbits $(96,97)$ which were fed with terpene rich diets. However, it is not certain that these dispositional characteristics can be extrapolated to humans, particular in view of the relatively large doses administered to animals. Terpene concentration might affect the type of metabolite formed $(98,99)$.

Studies on metabolism of monoterpenes, carvone and pulgeon in humans using MICA (Metabolism of Ingestion Correlated Amounts) approach have been carried out. 
Metabolites formed were identified as $\alpha, 4$-dimethyl-5-oxo3-cyclohexene-1-acetic acid (dihydrocarvonic acid), $\alpha$-methylene-4-methyl-5-oxo-3-cyclohexene-1-acetic acid (carvonic acid), and 5-(1,2-dihydroxy-1-methylethyl)-2methyl-2-cyclohexen-1-one (uroterpenolone) on the basis of mass spectral analysis in combination with synthesis and NMR experiments of the acidic fraction. Minor metabolites were identified as reduction products of carvone, namely, the alcohols carveol and dihydrocarveol. The previously identified major in vivo metabolite in rabbits, 10-hydroxycarvone (97), could not be detected, indicating either concentration dependent effect or interspecies differences. No differences in metabolism between $S-(+)$ and $R$ - $(-)$-carvone were detected (100).

There have been several studies of $(R)-(+)$ - and $(S)-(-)$ pulegone metabolism in rats (99-103), ex vivo experiments with rat liver microsomes (104-107) and human cytochrome P450 enzymes (108). Engel identified 2-(2-hydroxy-1methylethyl)-5-methylcyclohexanone (8-hydroxymenthone), 3-hydroxy-3-methyl-6-(1-methylethyl)cyclohexanone (1hydroxymenthone), 3-methyl-6-(1- ethylethyl)cyclohexanol (menthol), and E-2-(2-hydroxy- 1-methylethylidene)-5methylcyclohexanone (10-hydroxypulegone) as the four major metabolites of pulegone. 10-hydroxypulegone was identified as a minor metabolite of $(S)-(-)$-pulegone. However, it was one of the major metabolites of $(R)-(+)$-pulegone. In addition, 3-methyl-6-(1-methylethyl)-2-cyclohexenone (piperitone,) and R,R,4-trimethyl-1- cyclohexene-1-methanol (3-p-menthen-8-ol) were identified as minor metabolites (109). Menthofuran was identified early as a metabolite of pulegone formed after ingestion of large amounts of pennyroyal oil (110), however it was later found that menthofuran was most probably an artifactual product formed during workup from known (10-hydroxypulegone) and/or unknown precursors. The reaction of 10-hydroxypulegone forming menthofuran is considerably faster in aqueous solution at room temperature at any $\mathrm{pH}$, leading to complete transformation of 10-hydroxypulegone to menthofuran, usually within hours. Therefore, this reaction was considered as a major source of menthofuran. As a consequence, the amount of menthofuran detected in metabolism experiments was strongly dependent on the workup method. The precursor, 10 -acetoxypulegone, was also unstable and it slowly isomerized to form 9-acetoxypulegone (111). Engel was not able to clarify that $p$-cresol was a major metabolite of menthofuran and, therefore, whether it was responsible for the toxic effects associated with pulegone ingestion. The difference in toxicity between $(S)-(-)$ - and $(R)-(+)$-pulegone could be explained by the strongly diminished ability for enzymatic reduction of the double bond in (R)-(+)-pulegone, which might lead to further oxidative metabolism of 10-hydroxypulegone and the formation of currently undetected metabolites. These metabolites could possibly account for the observed hepatotoxic and pneumotoxic activity observed in humans (109).

\section{CONCLUSION}

Terpenes, the naturally occurring volatile oils, appear to be clinically acceptable penetration enhancers as indicated by high percutaneous enhancement ability, reversible effect on the lipids of SC, minimal percutaneous irritancy at low concentration $(1-5 \%)$ and good evidence of freedom from toxicity. Moreover, a variety of terpenes have been shown to increase percutaneous absorption of both hydrophilic and lipophilic drugs when judiciously selected and combined with solvents. Hence, use of terpenes can be expected to yield satisfactory permeation of drugs across skin from transdermal formulations. However, proper selection of terpenes based on the functional groups, $\log p$ values, metabolic disposition would be important. However, it seems more rationale and essential to actually test the terpene containing formulations in humans in order to arrive at a reliable conclusion regarding systemic efficacy of the transdermal patches.

\section{REFERENCES}

1. T. Kurihara-Bergstrom, and W. R. Good. Skin development and permeability. J. Control. Release 6:51-58 (1987).

2. J. Shokri, A. Nokhodchi A. Dashbolaghi, et al. The effect of surfactants on the skin penetration of diazepam. Int. J. Pharm. 228:99-107 (2001).

3. N. Kannikkannan, K. Kanimalla S. S. Lamba, et al. Structure activity relationship of chemical penetration enhancers in transdermal drug activity. Cur. Med. Chem. 7:603-608 (2003).

4. B. J. Aungst, N. J. Rogers, and E. Shefter. Enhancement of naloxone penetration through human skin in vitro using fatty acids, fatty alcohols, surfactants, sulfoxides and amides. Int. $J$. Pharm. 3:225-234 (1986)

5. H. Okabe, E. Suzuki T. Saitoh, et al. Development of novel transdermal system containing $d$-limonene and ethanol as absorption enhancers. J. Control. Release 32:243-247 (1994).

6. U. T. Lashmar, J. Hadgraft, and N. Thomas. Topical application of penetration enhancers to the skin of nude mice; a histopathological study. J. Pharm. Pharmacol. 41:118-122 (1989).

7. H. Okamoto, M. Ohyabu M. Hashida, et al. Enhanced penetration of mitomycin $\mathrm{C}$ through hairless mouse and rat skin by enhancers with terpene moieties. J. Pharm. Pharmacol. 39:531-534 (1987).

8. R. A. Thakur, Y. Wang, and B. B. Michniak. Essential oils and terpenes. In E. W. Smith, and H. I. Maibach (eds.), Percutaneous Penetration Enhancers, CRC Press, Boca Raton, 2006, pp. 159-173.

9. A. C. Williams, and B. W. Barry. Terpenes and the lipidprotein-partitioning theory of skin penetration enhancement Pharm. Res. 8:17-24 (1991).

10. FDA. Part 182 substances generally recognized as safe. http:// www.cfsan.fda.gov/ Ird/fcf182.html. Acessed on Nov 30, 2006.

11. M. A. Yamane, A. C. Williams, and B. W. Barry. Effects of terpenes and oleic acid as skin penetration enhancers towards 5-fluorouracil as assessed with time; permeation, partitioning and differential scanning calorimetry. Int. J. Pharm. 116:237-251 (1995).

12. M. A. Yamane, A. C. Williams, and B. W. Barry. Terpene penetration enhancers in propylene glycol/water co-solvent systems: Effectiveness and mechanism of action. J. Pharm. Pharmacol. 47:978-989 (1995).

13. A. F. El-Kattan, C. S. Asbill N. Kim, et al. The effects of terpene enhancers on the percutaneous permeation of drugs with different lipophilicities. Int. J. Pharm. 215:229-240 (2001).

14. P. F. C. Lim, X. Y. Liu L. Kang, et al. Limonene GPI/PG organogel as a vehicle in transdermal delivery of haloperidol. Int. J. Pharm. 311:157-164 (2006).

15. N. González, and H. Sumano. Design of two liquid ibuprofenpoloxamer-limonene or menthol preparations for dermal administration. Drug Deliv. 14:287-293 (2007).

16. T. Tas, Y. Ozkan, A. Okyar, and A. Savaser. In vitro and ex vivo permeation studies of etodolac from hydrophilic gels and effect of terpenes as enhancers. Drug Deliv. 14:453-459 (2007).

17. H. K. Vaddi, P. C. Ho Y. W. Chan, et al. Oxide terpenes as human skin penetration enhancers of haloperidol from ethanol 
and propylene glycol and their modes o action on stratum corneum. Biol. Pharm. Bull. 26:220-228 (2003).

18. B. M. Magnusson, P. Runn K. Karlsson, et al. Terpenes and ethanol enhance the transdermal permeation of the tripeptide thyrotropin releasing hormone in human epidermis. Int. $J$. Pharm. 157:113-121 (1997).

19. S. T. K. Narishetty, and R. Panchagnula. Transdermal delivery of zidovudine: Effect of terpenes and their mechanism of action. J. Control. Release 95:367-379 (2004).

20. S. T. K. Narishetty, and R. Panchagnula. Effect of L-menthol and 1,8-cineole on phase behavior and molecular organization of SC lipids and skin permeation of zidovudine. J. Control. Release 102:59-70 (2005).

21. Y. S. R. Krishnaiah, V. Satyanarayana, and R. S. Karthikeyan. Penetration enhancing effect of menthol on the percutaneous flux of nicardipine hydrochloride through excised rat epidermis from hydroxypropyl cellulose gels. Pharm. Dev. Tech. 7:305-315 (2002).

22. T. T. Kararli, C. F. Kirchhoff, and S. C. Penzotti. Enhancement of transdermal transport of azidothymidine (AZT) with novel terpene and terpene like enhancers: In vivo-in vitro correlations. J. Control. Release 34:43-51 (1995).

23. Y. S. R. Krishnaiah, V. Satyanarayana, and P. Bhaskar. Enhanced percutaneous permeability of nicardipine hydrochloride by carvone across the rat abdominal skin. Drug Dev. Ind. Pharm. 29:191-202 (2003).

24. Y. S. R. Krishnaiah, P. Bhaskar, and V. Satyanarayana. Penetration enhancing effect of ethanol-water solvent system and ethanolic solution of carvone on transdermal permeability of nimodipine from HPMC gel across rat abdominal skin. Pharm. Dev. Tech. 1:63-74 (2004).

25. A. Nokhodchi, K. Sharabiani M. R. Rashidi, et al. The effect of terpene concentrations on the skin penetration of diclofenac sodium. Int. J. Pharm. 335:97-105 (2007).

26. H. K. Vaddi, P. C. Ho Y. W. Chan, et al. Terpenes in ethanol: Haloperidol permeation and partition through human skin and stratum corneum changes. J. Control. Release 81:121-133 (2002).

27. H. K. Vaddi, P. C. Ho, and S. Y. Chan. Terpenes in propylene glycol as skin-penetration enhancers: permeation and partition of haloperidol, Fourier transform infrared spectroscopy, and differential scanning calorimetry. J. PharmSci. 91:639-1651 (2002).

28. B. F. Van Duzee. Thermal analysis of human stratum corneum. J. Invest. Dermatol. 65:404-408 (1975).

29. G. M. Golden, D. B. Guzek R. R. Harris, et al. Lipid thermotropic transitions in human stratum corneum. J. Invest. Dermatol. 86:255-259 (1986).

30. K. Zhao, and J. Singh. Mechanisms of percutaneous absorption of tamoxifen by terpenes: Eugenol, $d$-limonene and menthone. J. Control. Release 55:253-260 (1998).

31. O. Pillai, and R. Panchagnula. Transdermal iontophoresis of insulin V. Effect of terpenes. J. Control. Release 88:287-296 (2003).

32. K. Knutson, R. O. Potts D. B. Guzek, et al. Macro and molecular physical chemical considerations in understanding drug transport in the stratum corneum. J. Control. Release 2:6787 (1985).

33. H. Tori, and M. Tasumi. Theoretical analyses of the amide I infrared bands of globular proteins. In H. H. Mantsch, and D. Chapman (eds.), Infrared Spectroscopy of Biomolecules, WileyLiss, New York, 1996, pp. 1-18.

34. B. Norman Grainger, and W. Max. Herbal Drugs and Phytopharmaceuticals, A Handbook for Practice on a Scientific Basis with Reference to German Commission E Monographs, 2nd edn, CRC Press, New York, 2001.

35. D. Monti, P. Chetoni S. Burgalassi, et al. Effect of different terpene containing essential oils on permeation of estradiol through hairless mouse skin. Int. J. Pharm. 237:209-214 (2002)

36. H. Okabe, K. Takayama T. Nagai, et al. Effect of $d$-limonene and related compounds on the percutaneous absorption of indomethacin. Drug Des. Deliv. 4:313-321 (1989).

37. K. Kikuchi, K. Takayama, and T. Nagai. Effect of $d$-limonene on the amounts of ethanol and indomethacin penetrated from aqueous gel ointment to rat skin. Chem. Pharm. Bull. 40:31083109 (1992).

38. H. Okabe, K. Takayama, and T. Nagai. Percutaneous absorption of ketoprofen from acrylic gels patches containing $d$ limonene and ethanol as absorption enhancers. Chem. Pharm. Bull. 40:1906-1910 (1992).

39. N. Ohara, K. Takayama Y. Machida, et al. Combined effect of $d$-limonene and temperature on the skin permeation of ketoprofen. Int. J. Pharm. 105:31-38 (1994).

40. Y. S. R. Krishnaiah, D. V. Chandrasekhar B. Rama, et al. In vivo evaluation of limonene based transdermal therapeutic system of nicorandil in healthy human volunteers. Skin Pharmacol. Physiol. 18:263-272 (2005).

41. M. Hori, S. Satoh H. I. Maibach, et al. Enhancement of propranolol hydrochloride and diazepam skin absorption in vitro: Effect of enhancer lipophilicity. J. Pharm. Sci. 80:32-35 (1991).

42. H. Moghimi, A. Williams, and B. Barry. A lamellar matrix model for stratum corneum intercellular lipids. V. Effects of terpene penetration enhancers on the structure and thermal behavior of the matrix. Int. J. Pharm. 146:41-54 (1997).

43. H. Okabe, Y. Obata K. Takayama, et al. Percutaneous absorption enhancing effect and skin irritation of monocyclic monoterpenes. Drug Des. Del. 6:229-238 (1990).

44. C. K. Lee, T. Uchida K. Kitagawa, et al. Effect of hydrophilic and lipophilic vehicles on skin permeation of tegafur, alclofenac and ibuprofen with or without permeation enhancers. Biol. Pharm. Bull. 16:1264-1269 (1993).

45. C. K. Lee, T. Uchida K. Kitagawa, et al. Skin permeability of various drugs with different lipophilicity. J. Pharm. Sci. 83:562565 (1994)

46. C. A. Phillips, and B. B. Michniak. Transdermal delivery of drugs with differing lipophilicities using azone analogs as dermal penetration enhancers. J. Pharm. Sci. 84:1427-1433 (1995).

47. J. Borrras-Blasco, A. Lopez M. Morant, et al. Influence of sodium lauryl sulfate on in vitro percutaneous absorption of compounds with different lipophilicity. Eur. J. Pharm. Sci. 5:1522 (1997).

48. D. A. Godwin, and B. B. Michniak. Influence of drug lipophilicity on terpenes as transdermal penetration enhancers. Drug Dev. Ind. Pharm. 25:905-915 (1999).

49. A. F. El-Kattan, C. S. Asbill N. Kim, et al. The effects of terpene enhancer lipophilicity on the percutaneous permeation of hydrocortisone formulated in HPMC gel systems. Int. J. Pharm. 198:179-199 (2000).

50. K. C. Sung, J. Fang, and H. O. Yoa-Pu. Delivery of nalbuphine and its prodrugs across skin by passive diffusion and iontophoresis. J. Control. Release 67:1-8 (2000).

51. C. M. Heard, D. Kung, and C. P. Thomas. Skin penetration enhancement of mefenamic acid by ethanol and 1,8-cineole can be explained by the 'pull' effect. Int. J. Pharm. 321:167-170 (2006).

52. J. L. V. Anjos, D. S. Neto, and A. Alonso. Effects of ethanol/lmenthol on the dynamics and partitioning of spin-labeled lipids in the stratum corneum. Eur. J. Pharm. Biopharm. 67:406-412 (2007).

53. Y. Kaplun-Frischoff, and E. Touitou. Testosterone skin permeation enhancement by menthol through formation of eutectic with drug and interaction with skin lipids. Eur. J. Pharm. Sci. 86:1394-1399 (1997).

54. J. R. Kunta, V. R. Goskonda, H. O. Brotherton, M. A. Khan, and I. K. Reddy. Effect of menthol and related terpenes on the percutaneous absorption of propranolol across excised hairless mouse skin. J. Pharm. Sci. 86:1369-1373 (1997).

55. S. Kitagawa, H. Li, and S. Sato. Skin permeation of parabens in excised guinea pig dorsal skin, its modification by penetration enhancers and their relationship with n-octanol/water partition coefficients. Chem. Pharm. Bull. 45:1354-1357 (1997).

56. D. Kobayashi, T. Matsuzawa K. Sugibayashi, et al. Analysis of the combined effect of 1-menthol and ethanol as skin permeation enhancers based on a two-layer skin model. Pharm. Res. 11:96-103 (1994).

57. Y. Maitani, K. Shimada, and T. Nagai. l-Menthol, oleic acid and lauricidin in absorption enhancement of free and sodium salt of 
diclofenac using ethanol treated silicone membrane as model for skin. Chem. Pharm. Bull. 44:403-408 (1996).

58. J. S. Chang, Y. H. Tsai P. C. Wu, et al. Effects of ethanol/lmenthol on the dynamics and partitioning of spin-labeled lipids in the stratum corneum. Eur. J. Pharm. Biopharm. 67:406-412 (2007).

59. J. L. V. Anjos, D. S. Neto, and A. Alonso. Effects of 1,8-cineole on the dynamics of lipids and proteins of stratum corneum. Int. J. Pharm. 345:81-87 (2007).

60. R. Prasad, V. Koul, S. Anand, and R. K. Khar. Effect of DC/ $\mathrm{mDC}$ iontophoresis and terpenes on transdermal permeation of methotrexate: In vitro study. Int. J. Pharm. 333:70-78 (2007).

61. J. Negishi, K. Takayama Y. Higashiyama, et al. Promoting effect of $O$-alkylmenthol and $O$-acylmenthol derivatives on the percutaneous absorption of ketoprofen in rats. STP Pharma. Sci. 5:156-164 (1995).

62. Y. Nakamura, K. Takayama K. Higashiyama, et al. Promoting effect of $O$-ethylmenthol on the percutaneous absorption of ketoprofen. Int. J. Pharm. 145:29-36 (1996).

63. Y. Obata, C. J. Li M. Fujikawa, et al. Evaluation of structure activity relationship of synthesized cyclohexanol derivatives on percutaneous absorption of ketoprofen using artificial neural network. Int. J. Pharm. 212:223-231 (2001).

64. Y. Obata, Y. Maruyama, and K. Takayama. The mode of promoting activity of $O$-ethylmenthol as a transdermal absorption enhancer. Pharm. Res. 23:392-400 (2006).

65. P. Cornwell, and B. W. Barry. Sesquiterpene components of volatile oils as skin penetration enhancers for the hydrophilic permeant 5-fluorouracil. J. Pharm. Pharmacol. 46:261-269 (1991).

66. A. Arellano, S. Santoyo C. Martin, et al. Enhancing effect of terpenes on the in vitro percutaneous absorption of diclofenac sodium. Int. J. Pharm. 130:141-145 (1996).

67. P. Cornwell, B. W. Barry C. P. Stoddart, et al. Wide angle X-ray diffraction of human stratum corneum: Effects of hydration and terpene enhancer treatment. J. Pharm. Pharmacol. 46:938-950 (1994).

68. G. L. Xiong, D. Quan, and H. I. Maibach. Effects of penetration enhancers on in vitro percutaneous absorption of low molecular weight heparin through human skin. J. Control. Release 42:289-296 (1996).

69. R. Kadir, and B. W. Barry. a-Bisabolol, a possible safe penetration enhancer for dermal and transdermal therapeutics. Int. J. Pharm. 70:87-94 (1991).

70. F. Yamashita, and M. Hashida. Mechanistic and empirical modeling of skin permeation of drugs. Adv. Drug. Deliv. Rev. 55:1185-1199 (2003).

71. G. L. Flynn. Physicochemical determinants of skin absorption. In T. Gerrity, and C. Henry (eds.), Principles of Route-to-Route Extrapolation for Risk Assessment, Elsevier, New York, 1990, pp. 93-127.

72. N. E. Tayar, R. S. Tsai B. Testa, et al. Percutaneous penetration of drugs: A quantitative structure-permeability relationship study. J. Pharm. Sci. 80:744-749 (1991).

73. R. O. Potts, and R. H. Guy. Predicting skin permeability. Pharm. Res. 9:663-669 (1992).

74. R. O. Potts, and R. H. Guy. A predictive algorithm for skin permeability: The effects of molecular size and hydrogen bond activity. Pharm. Res. 12:1628-1633 (1995).

75. E. J. Lien, and H. Gao. QSAR analysis of skin permeability of various drugs in man as compared to in vivo and in vitro studies in rodents. Pharm. Res. 12:583-587 (1995).

76. M. T. Cronin, J. C. Dearden G. P. Moss, et al. Investigation of the mechanism of flux across human skin in vitro by quantitative structure-permeability relationships. Eur. J. Pharm. Sci. 7:325-330 (1999)

77. G. P. Moss, J. C. Dearden H. Patel, et al. Quantitative structure permeability relationships (QSPRs) for percutaneous absorption. Toxicol. In Vitro 16:299-317 (2002).

78. S. Geinoz, S. Rey G. Boss, et al. Quantitative structurepermeation relationships for solute transport across silicone membranes. Pharm. Res. 19:1622-629 (2002).

79. S. Fujiwara, F. Yamashita, and M. Hashida. QSAR analysis of interstudy variable skin permeability based on the "latent membrane permeability" concept. J. Pharm. Sci. 92:1939-1946 (2003).
80. A. R. Katritzky, D. A. Dobchev D. C. Fara, et al. Skin permeation rate as a function of chemical structure. J. Med. Chem. 49:3305-3314 (2006).

81. I. T. Degim. New tools and approaches for predicting skin permeability. Drug Discov. Today 11:517-523 (2006).

82. D. Neumann, O. Kohlbacher C. Merkwirth, et al. A fully computational model for predicting percutaneous drug absorption. J. Chem. Inf. Model. 46:424-429 (2006).

83. T. Ghafourian, P. Zandasrar H. Hamishekar, et al. The effect of penetration enhancers on drug delivery through skin: A QSAR study. J. Control. Release 99:113-125 (2004).

84. S. Geinoz, R. H. Guy B. Testa, et al. Quantitative structurepermeation relationships (QSPeRs) to predict skin permeation: A critical evaluation. Pharm. Res. 21:83-92 (2004).

85. L. Kang, C. W. Yap P. F. C. Lim, et al. Formulation development of transdermal dosage forms: Quantitative structureactivity relationship model for predicting activities of terpenes that enhance drug penetration through human skin. J. Control. Release 120:211-219 (2007)

86. A. C. Williams, and B. W. Barry. Penetration enhancers. $A d v$. Drug Del. Dev. 56:603-618 (2004).

87. K. Cal. How does the type of vehicle influence the in vitro skin absorption and elimination kinetics of terpenes? Arch. Dermatol. Res. 297:311-315 (2006).

88. J. Y. Fang, T. H. Tsai, Y. Y. Lin, W. W. Wong, M. N. Wang, and J. F. Huang. Transdermal delivery of tea catechins and theophylline enhanced by terpenes: A mechanistic study. Biol. Pharm. Bull. 30:343-349 (2007).

89. Y. Krishnaiah, S. Al-Saidan, D. Chandrasekhar, and V. Satyanarayana. Controlled in vivo release of nicorandil from a carvone-based transdermal therapeutic system in human volunteers. Drug Del. 13:69-77 (2006).

90. Y. S. R. Krishnaiah, V. Satyanarayana, and P. Bhaskar. Influence of limonene on the bioavailability of nicardipine hydrochloride from membrane-moderated transdermal therapeutic systems in human volunteers. Int. J. Pharm. 247:91-102 (2002).

91. Y. S. Krishnaiah, V. Satyanarayana, and R. S. Karthikeyan. Penetration enhancing effect of menthol on the percutaneous flux of nicardipine hydrochloride through excised rat epidermis from hydroxypropyl cellulose gels. Pharm. Dev. Technol. 7:305315 (2002).

92. P. Ventura, M. Schiavi, and S. Serafini. The metabolism of transsobrerol in the rat. Xenobiotica 13:139-146 (1983).

93. P. Ventura, R. Pellegata, M. Schiavi, and S. Serafini. Biotransformation of trans-sobrerol. III. Metabolites of 8-hydroxycarvonacetone in the rat. Xenobiotica 16:317-323 (1986).

94. J. J. Diliberto, P. Srinivas O. Overstreet, et al. Metabolism of citral, an R, $\hat{a}$-unsaturated aldehyde, in male F344 rats. Drug Metab. Dispos. 18:866-875 (1990).

95. S. A. Kouzi, J. D. McChesney, and L. A. Walker. Identification of four bilinary metabolites of the diterpene sclareol in the laboratory rat. Xenobiotica 23:621-632 (1993).

96. Y. Asakawa, T. Ishida M. Toyota, et al. Terpenoid biotransformation in mammals IV. Biotransformation of $(+)$-longifolene, $(-)$-caryophyllene, $(-)$ - caryophyllene oxide, $(-)$-cyclocolorenone, $(+)$-nootkatone, $(-)$-elemol, (-)-abietic acid and $(+)-$ dehydroabietic acid in rabbits. Xenobiotica 16:753-767 (1986).

97. T. Ishida, M. Toyota, and Y. Asakawa. Terpenoid biotransformation in mammals. V. Metabolism of $(+)$-citronellal, (+/-)-7hydroxycitronellal, citral, (-)-perillaldehyde, (-)-myrtenal, cuminaldehyde, thujone, and $(+/-)$-carvone in rabbits. Xenobiotica 19:843-855 (1989).

98. K. A. Eriksson, and J. O. Levin. Identification of cis- and transverbenol in human urine after occupational exposure to terpenes Int. Arch. Occup. Environ. Health 62:379-383 (1990).

99. C. Köppel, J. Tenczer U. Tönnesmann, et al. Acute poisoning with pine oils metabolism of monoterpenes. Arch. Toxicol. 49:73-78 (1981).

100. W. Engel. In vivo studies on the metabolism of the monoterpenes $S-(+)$ - and $R-(-)$-carvone in humans using the metabolism of ingestion-correlated amounts (MICA) approach J. Agric. Food Chem. 49:4069-4075 (2001).

101. B. Moorthy, P. Madyashtha, and K. M. Madyastha. Metabolism of a monoterpene ketone, $R-(+)$-pulegonesa hepatotoxin in rat. Xenobiotica 19:217-224 (1989). 
102. K. M. Madyastha, and N. W. Gaikwad. Metabolic fate of $S-(-)-$ pulegone in rat. Xenobiotica 28:723-734 (1998).

103. K. M. Madyastha, and C. Paul Raj. Studies on the metabolism of a monoterpene ketone, $R-(+)$-pulegonesa hepatotoxin in rat: Isolation and characterization of new metabolites. Xenobiotica 23:509-518 (1993).

104. P. Madyastha, B. Moorthy C. S. Vaidyanathan, et al. In vivo and in vitro destruction of rat liver cytochrome $P-450$ by a monoterpene ketone, pulegone. Biochem. Biophys. Res. Commun. 128:921-927 (1985).

105. L. J. Chen, E. H. Lebetkin, and L. T. Burka. Metabolism of $(R)-(+)-$ pulegone in F344 rats. Drug Metab. Dispos. 29:1567-1577 (2001).

106. K. M. Madyastha, and C. Paul Raj. Biotransformations of $R-(+)$ pulegone and menthofuran in vitro: Chemical basis for toxicity. Biochem. Biophys. Res. Commun. 173:1086-1092 (1990).

107. K. M. Madyastha, and B. Moorthy. Pulegone mediated hepatotoxicity: Evidence for covalent binding of $R-(+)-[14 \mathrm{C}]$ pulegone to microsomal proteins in vitro. Chem. Biol. Interact. 72:325-333 (1989).

108. S. C. Khojasteh-Bakht, W. Chen L. L. Koenigs, et al. Metabolism of $(R)-(+)$-pulegone and $(R)-(+)$ - menthofuran by human liver cytochrome $P-450$ s: Evidence for formation of a furan epoxide. Drug Metab. Dispos. 27:574-580 (1999).

109. W. Engel. In vivo studies on the metabolism of the monoterpene pulegone in humans using the metabolism of ingestioncorrelated amounts (MICA) approach: Explanation for the toxicity differences between $(S)-(-)$ - and $(R)-(+)$-pulegone. $J$. Agric. Food Chem. 51:6589-6597 (2003).

110. W. P. Gordon, A. C. Huitric C. L. Seth, et al. The metabolism of the abortifacient terpene, $(R)-(+)$-pulegone, to a proximate toxin, menthofuran. Drug Metab. Dispos. 15:589-594 (1987).

111. K. M. Madyastha, and C. Paul Raj. Evidence for the formation of a known toxin, p-cresol from menthofuran. Biochem. BiophysRes. Commun. 177:440-446 (1991). 